\title{
Effect of mtDNA depletion from C6 glioma cells and characteristics of the generated $\mathrm{C6 \rho 0}$ cells
}

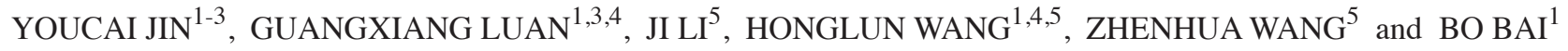 \\ ${ }^{1}$ Key Laboratory of Tibetan Medicine Research, Northwest Institute of Plateau Biology, Chinese Academy of Sciences; \\ ${ }^{2}$ College of Chemistry and Chemical Engineering, Qinghai Normal University, Xining, Qinghai 810008; \\ ${ }^{3}$ University of Chinese Academy of Sciences, Beijing 100049; ${ }^{4}$ Key Laboratory of Tibetan Medicine Research of \\ Qinghai Province, Northwest Institute of Plateau Biology, Chinese Academy of Sciences, Xining, Qinghai 810008; \\ ${ }^{5}$ Center for Mitochondria and Healthy Aging, College of Life Sciences, Yantai University, Yantai, Shandong 264005, P.R. China
}

Received April 25, 2020; Accepted December 8, 2020

DOI: $10.3892 / \mathrm{mmr} .2021 .11904$

\begin{abstract}
Malignant tumors of the central nervous system (CNS) are among the types of cancer with the poorest prognosis and glioma is the commonest primary CNS tumor. A mitochondrial DNA (mtDNA)-depleted cell line C6 $\rho 0$ was generated from C6 glioma cells after long-term exposure to ethidium bromide and 2',3'-dideoxycytidine in order to determine the effect of mtDNA damage on cell proliferation and pathological changes in glioma cells. Single cell clones were isolated and identified after 42 days of incubation. Repopulated cybrids were formed when the clonal C $6 \rho 0$ cells were fused with rat platelets and no difference was observed in their growth in a selective medium without uridine and pyruvate compared with the growth of the parent C6 cells. Disruption of mtDNA resulted in changes in mitochondrial morphology, decreased cell proliferation, reduced intracellular reactive oxygen species and intracellular ATP, along with decreased mtDNA and mitochondrial membrane potential in C $6 \rho 0$ cells compared with the C6 cells. Taken together, C6 $\rho 0$ cells without mtDNA were established for the first time and their characteristics were compared with parent cells. This C6 00 cell line could be used to explore the contribution of mitochondrial dysfunction and mtDNA mutations in the pathogenesis of glioma.
\end{abstract}

Correspondence to: Dr Bo Bai, Key Laboratory of Tibetan Medicine Research, Northwest Institute of Plateau Biology, Chinese Academy of Sciences, 23 Xinning Road, Xining, Qinghai 810008, P.R. China

E-mail: baibochina@163.com

Professor Zhenhua Wang, Center for Mitochondria and Healthy Aging, College of Life Sciences, Yantai University, 30 Qingquan Road, Yantai, Shandong 264005, P.R. China

E-mail: zhenhuawang@tom.com

Key words: C6 glioma, 0 , mitochondrial DNA, cytoplasmic hybrids, mitochondrial

\section{Introduction}

Malignant tumors of the central nervous system (CNS) are among the types of cancer with the poorest prognosis, with high levels of morbidity and mortality (1). Glioma is the most common primary CNS tumor deriving from neuroglial stem or progenitor cells (2). Mitochondrial DNA (mtDNA) mutations have been found to be closely associated with various types of cancer, neurodegenerative disorders, attention-deficit hyperactivity disorder, headache, diabetes and aging (3-8). Therefore, a study on the effect of mtDNA heterogeneity on glioma growth, differentiation and death is required. Mitochondria serve a crucial and integral role in maintaining cell homeostasis, including energy synthesis, redox regulation, cell messaging and hematopoiesis $(9,10)$ and they provide $\sim 80-90 \%$ of the energy to the cell through the respiratory chain and this percentage reaches $95 \%$ in the heart $(11,12)$. Furthermore, mitochondria regulate apoptosis and cell cycle through their role in several processes including calcium signaling, reactive oxygen species (ROS) homeostasis, biosynthesis of heme, biosynthesis of iron-sulfur clusters and tumorigenesis (13).

Since mtDNA mutations can compromise the mitochondrial function and lead to human pathologies, there is a strong and continuing interest in their role in human health and disease. Unfortunately, the study of mtDNA mutations is not easy due to the nuclear background diversity and the role it serves in the modulation of mitochondrial defects (14). Fortunately, hybrid technology provides a new strategy to study diseases associated with mitochondrial dysfunctions. The technique is based on the use of a cell line in which the mtDNA is depleted ( $\rho 0$ cells) and can be used as a mitochondrial receptor when fused with platelets $(15,16)$. Since cytoplasmic hybrids (cybrids) have the same genetic background, biochemical analysis is made possible. Previous studies have demonstrated that ethidium bromide (EB), 2',3'-dideoxycytidine (ddC), rhodamine-6g, 1-methyl-4-phenylpyridinium, zidovudine and stavudine, together with NT2 human teratocarcinoma, T47d human breast cancer cells, 143B human bone osteosarcoma thymidine kinase negative (TK-) and human mesenchymal stem cell (3a6 and KP) are commonly used to produce $\rho 0$ cells $(13,17-19)$. 
Therefore, in the present study, the mtDNA-depleted cell line $\mathrm{C} 6 \rho 0$ was generated from C6 glioma cells and the mtDNA-related deficits were determined. The results demonstrated that C6 $\rho 0$ cells could be a useful tool in the investigation of mitochondrial dysfunction and mtDNA mutations and their role in the pathogenesis of glioma can be also evaluated.

\section{Materials and methods}

C6 cell culture and isolation of $C 6 \rho 0$ clone cell line. The rat C6 glioma cell line was purchased from the Institute of Culture Collection of the Chinese Academy of Sciences and cultured in F-12 Ham medium (Gibco; Thermo Fisher Scientific, Inc.) supplemented with $2 \%$ fetal bovine serum (Zhejiang Tianhang Biotechnology Co., Ltd.), 15\% horse serum (Tianjin Kangyuan Biotechnology Co., Ltd.) and $1 \%$ penicillin (100 U/ml) and streptomycin $(100 \mu \mathrm{g} / \mathrm{ml}$; both from Corning, Inc.). The medium was changed every three days and sub-cultures were made when the cells reached $80 \%$ confluence. The cells were maintained at $37^{\circ} \mathrm{C}, 5 \% \mathrm{CO}_{2}$ and $90 \%$ humidity.

The generation of $\mathrm{C} 6 \rho 0$ cells was performed by exposing wild-type $\mathrm{C} 6$ glioma cells to $5 \mu \mathrm{M}$ EB and $8 \mu \mathrm{M}$ ddC in F-12 Ham medium supplemented with uridine $(50 \mu \mathrm{g} / \mathrm{ml})$ and pyruvate $(0.1 \mathrm{mg} / \mathrm{ml})$, with a daily change of the culture medium. Cells $\left(2 \times 10^{6}\right)$ were incubated in the above medium at $37^{\circ} \mathrm{C}$, $5 \% \mathrm{CO}_{2}$ and $90 \%$ humidity and the expression of mtDNA was measured using a mtDNA-specific PCR for a set period of time until mtDNA band completely disappeared.

Single cell clones were isolated and collected by the limiting dilution method (16) when the mtDNA band disappeared. When no mtDNA fragment was detected by PCR, the treated cells were quickly plated into 96-well plates at a density of one cell per well to isolate pure cell clones derived from the heterogeneous colony. Screening and isolation of C6 $\rho 0$ cells were performed as shown in Fig. 1.

A single colony in 96-well was observed under an inverted phase contrast microscope (Olympus Corporation); a single C6 00 cell was marked and the wells containing $>2$ cells were discarded. When the single colony was spread in the 96-well plate, it was transferred into 48, 24, 12 and 6-well plates one after the other after spreading the cells in each of them to gradually expand the cell amount. To verify the absence of mtDNA, each potential C6 $\rho 0$ cell line was divided into two halves: One half was used to study the survival ability in pyrimidines and pyruvate-absent $\mathrm{C} 6 \rho 0$ test medium and the other half was cultured in F-12 Ham medium containing uridine $(50 \mu \mathrm{g} / \mathrm{ml})$ and pyruvate $(0.1 \mathrm{mg} / \mathrm{ml})$. Trypan blue at a dose of $0.2 \%$ was used to test and count the viable cells. Finally, the $\mathrm{C} 6 \rho 0$ characteristic in these isolated colonies was confirmed by mtDNA-specific PCR.

To evaluate cell growth, C6 and C6 $\rho 0$ cells were plated in triplicate and the number of cells were counted on five consecutive days. In order to standardize the condition of the cell culture, C6 and C6 $\rho 0$ cells were cultured in F-12 Ham medium supplemented with $50 \mu \mathrm{g} / \mathrm{ml}$ uridine and $0.1 \mathrm{mg} / \mathrm{ml}$ pyruvate to evaluate the growth characteristics.

Production of transmitochondrial cybrids. The fusion between $\mathrm{C} 6 \rho 0$ and rat blood platelets was performed using the approach of standard chemical enucleation/polyethylene glycol fusion (18). The fusion cells were placed on a test bench for $1 \mathrm{~min}$ at $25^{\circ} \mathrm{C}$ and diluted with a mixture $(10 \mathrm{ml})$ of $\mathrm{F}-12$ Ham and FBS $(10 \%)$ supplemented with uridine $(50 \mu \mathrm{g} / \mathrm{ml})$ and pyruvate $(0.1 \mathrm{mg} / \mathrm{ml})$ and the suspension was placed into petri dishes ( 5 dishes, $2 \times 10^{5}$ cells/dish). The medium was replaced with the selective medium (without pyruvate and uridine) after 3 days.

PCR analysis of mtDNA. In order to detect mtDNA in C6, C6 $\rho 0$ and cybrids, total DNA from a different number of cells was isolated as a template using a commercial kit (Tiangen Biotech Co., Ltd.), following the manufacturer's instructions. Oligonucleotide primers were used to amplify the nucleotide sequences of rat mtDNA mitochondrial D-loop region. The primers were synthesized by Sangon Biotech Co., Ltd. mtDNA was amplified using a volume of $50 \mu \mathrm{l}$ containing $0.25 \mu \mathrm{l}$ units of TakaRa Ex Taq polymerase (Takara Biotechnology Co., Ltd.) and $0.2 \mu \mathrm{l}$ primer pair. Primers specific for the mtDNA D-loop region were the following: Forward 5'-CCTCCCATT CATTATCGCCGCCCTTGC-3' and reverse 5'-GTCTGG GTCTCCTAGTAGgTCTGGGAA-3' (235 bp). The PCR conditions were: 35 cycles of denaturation at $98^{\circ} \mathrm{C}$ for $10 \mathrm{sec}$, annealing at $60^{\circ} \mathrm{C}$ for $30 \mathrm{sec}$ and extension at $72^{\circ} \mathrm{C}$ for $60 \mathrm{sec}$. The products were separated by $1 \%$ agarose gel electrophoresis and images were detected using a 5200 Multi Luminescent image analyzer, according to the manufacturer's protocol (Tanon Science and Technology Co., Ltd.). The intensity of the bands indicated the amount of mtDNA.

Transmission electron microscopy (TEM). Cells for TEM were collected and plated on coverglasses according to the method of Kukat et al (20). Cells grown on cover slips were fixed with a solution of $2.5 \%$ glutaraldehyde in $100 \mathrm{mM}$ cacodylate buffer, $\mathrm{pH} 7.4$ for $1.5 \mathrm{~h}$ at $4^{\circ} \mathrm{C}$, washed twice with cacodylate buffer, followed by a fixation with $2 \%$ osmium tetroxide in $50 \mathrm{mM}$ cacodylate buffer ( $\mathrm{pH}$ 7.4). Specimens were washed twice with distilled water and stained over night with aqueous $0.5 \%$ uranyl acetate at $4^{\circ} \mathrm{C}$. Cells were dehydrated, embedded in Epon 812 and sectioned at $60 \mathrm{~nm}$. Mitochondrial morphology was observed using a $\mathrm{H} 7000$ electron microscope at $80 \mathrm{kV}$ (Hitachi, Ltd.). Negatives were digitized by scanning and processed with Adobe Photoshop CC (Adobe Systems, Inc.).

Mitochondrial mass change and sugar uptake. Cells ( $2 \times 10^{6}$ cells) were plated in $35 \mathrm{~mm}$ dishes for $24 \mathrm{~h}$ and incubated with 100 nM Mito-Tracker Green (Thermo Fisher Scientific, Inc.) or $10 \mu \mathrm{M} 2-\mathrm{NBDG}$, a fluorescent glucose, for $30 \mathrm{~min}$ at $37^{\circ} \mathrm{C}$ in the dark, to analyze the mitochondrial mass and sugar intake. Cells were detached by trypsin, collected, resuspended in saline solution and analyzed by flow cytometry. In each measurement, fluorescence intensity data from $2 \times 10^{4}$ single cell events were collected by an ACEA NovoCyte2040R flow cytometer (ACEA Bioscience, Inc.; Agilent Technologies, Inc.), using fluorescence excitation/emission (Ex/Em) wavelengths of $490 / 516 \mathrm{~nm}$ to evaluated the mitochondrial mass and Ex/Em of 480/525 nm to evaluate cell sugar uptake.

ATP consumption by C6 and C6 0 . An enhanced ATP Assay kit (Beyotime Institute of Biotechnology) was used to evaluate cellular ATP levels following the manufacturer's 


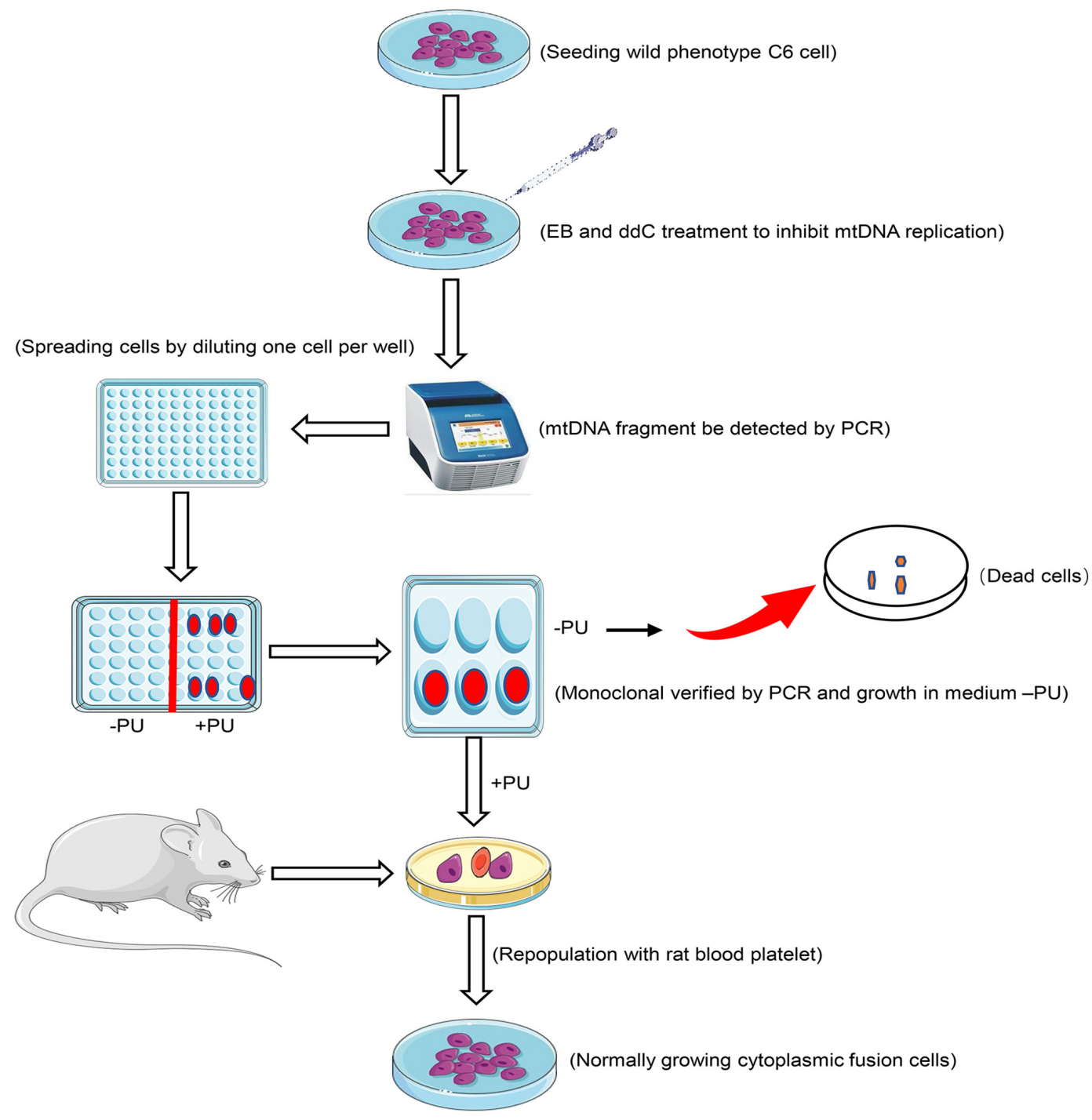

Figure 1. Schematic diagram of the protocol used to isolate the target cells and to generate fusion cells. EB, ethidium bromide; ddC, 2',3'-dideoxycytidine; mtDNA, mitochondrial DNA; -PU, growth in a medium without pyruvate and uridine; +PU, growth in a medium supplemented with pyruvate and uridine.

instructions. The cell lysates were centrifuged $(12,000 \mathrm{x} \mathrm{g}$ at $4^{\circ} \mathrm{C}$ for $5 \mathrm{~min}$ ) and the supernatant was collected and transferred into a 96-well plate containing the detection solution. The samples were then incubated for $30 \mathrm{~min}$ at $37^{\circ} \mathrm{C}$ and the luminescence signal was detected. Total ATP levels were calculated from the relationship between luminescence signals and protein concentration.

Detection of cellular reactive oxygen species (ROS) production. Cells were plated in $35 \mathrm{~mm}$ dishes $\left(2 \times 10^{6}\right.$ cells $)$ for $24 \mathrm{~h}$ and incubated with 2,7-dichlorodihydrofluorescein diacetate (DCFH-DA; $10 \mu \mathrm{M}$; Sigma-Aldrich; Merck KGaA) or $5 \mu \mathrm{M}$ MitoSOX Red (Thermo Fisher Scientific, Inc.) for $30 \mathrm{~min}$ at $37^{\circ} \mathrm{C}$ in the dark to analyze total ROS and mitochondrial ROS, respectively. Cells were detached by trypsin, collected, resuspended in saline solution and analyzed by a NovoCyte 2040R (ACEA Biosciences Inc.) flow cytometer. $\mathrm{Ex} / \mathrm{Em}$ of $480 / 525$ was set for the evaluation of total ROS, while Ex/Em of 510/580 was set for the evaluation of mitochondrial ROS. The amount of ROS produced was expressed as fluorescence intensity relative to the one of untreated cells.
Determination of mitochondrial membrane potential $(\Delta \Psi \mathrm{m})$. Cells were plated in dishes $\left(2 \times 10^{6}\right.$ cells) containing F-12 Ham medium for $24 \mathrm{~h}$ prior to the detection of $\Delta \Psi \mathrm{m}$. The cells were then collected, washed and resuspended in phosphate-buffered saline. Finally, $10 \mu \mathrm{M}$ JC-1 (Beijing Solarbio Science \& Technology Co., Ltd.) stain was added into the buffer and carbonyl cyanide m-chlorphenizonea, a potent mitochondrial membrane disruptor, was used as the positive control. The cells were incubated for $30 \mathrm{~min}\left(37^{\circ} \mathrm{C} ; 5 \% \mathrm{CO}_{2}\right)$ and then fluorescence intensity of $1 \times 10^{5}$ single cell events was processed by a NovoCyte 2040R flow cytometer (ACEA Biosciences Inc.) according to the manufacturer's protocol. Ex/Em of 490/530 and $\mathrm{Ex} / \mathrm{Em}$ of 525/590 was used for ratio analysis. The ratio of red/green (PE/FITC) fluorescence intensity was used to determine $\Delta \Psi \mathrm{m}$.

Statistical analysis. Statistical analysis was performed using GraphPad Prism software (version 6; GraphPad Software, Inc.). Results were presented as means \pm standard deviation $(n=3)$. Comparisons among multiple groups were analyzed using one-way ANOVA followed by Bonferroni's post hoc test. 


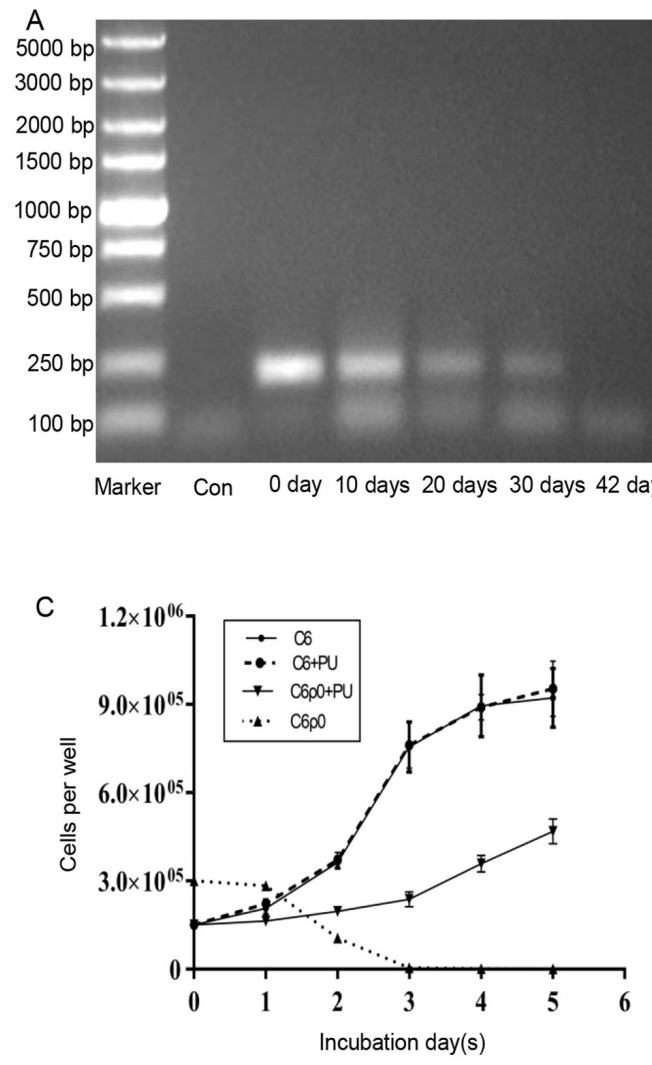

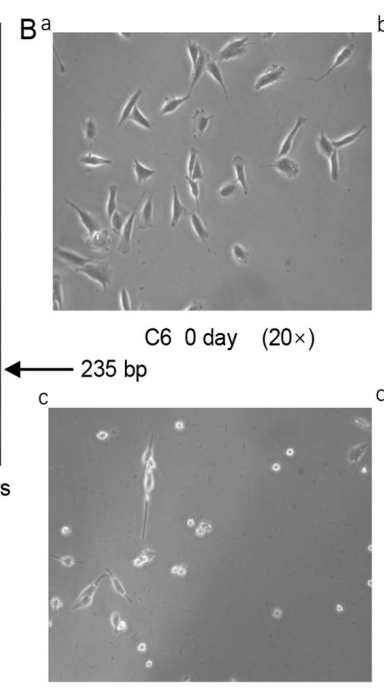

C6 $\rho 03$ days(-PU.) (20x)

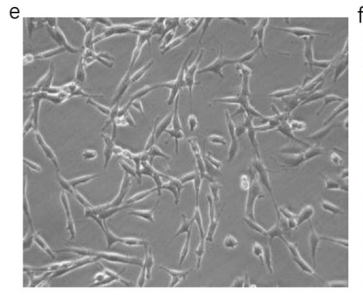

C6p0 5 days(+PU) (20x)

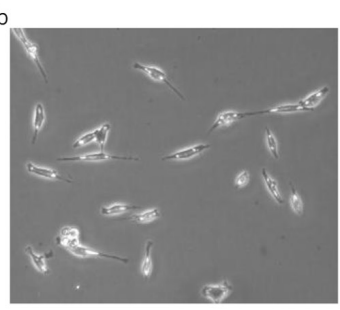

C6p0 0 day (-PU) (20x)

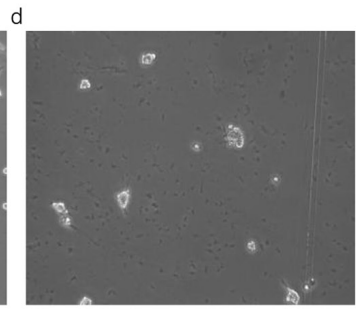

C6p0 5 days(-PU) (20x)

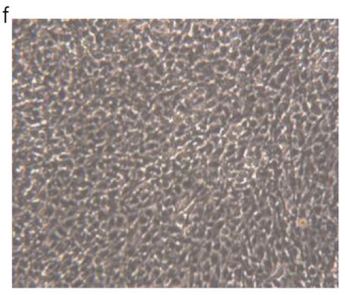

C6 5 days $(20 x)$

Figure 2. Establishment of $\mathrm{C} 6 \rho 0$ cells and growth characteristic of $\mathrm{C} 6$ and $\mathrm{C} 6 \rho 0$ cells in different media. (A) Cells were treated with EB $(5 \mu \mathrm{M})$ and ddC $(8 \mu \mathrm{M})$ for 6 weeks. The same amount of $\mathrm{C} 6$ cells $\left(4 \times 10^{5}\right)$ was used in the different groups. The content of mtDNA was determined by an mtDNA-specific PCR. The PCR products were visualized on $1 \%$ agarose gel by EB staining. Marker: 5000 DNA ladder. (B) Representative images of C6 and C6 0 clone cells growing in different media and at a different time points. (B-a and f) C6 cells were cultured in F-12 medium at day 0 and day 5, respectively. (B-b, c and d) C6 0 cells cultured in F-12 (-PU) at day 0, day 3 and day 5, respectively. (B-e) C6 $\rho 0$ cells cultured in F-12 (+PU) medium at day 5. (C) C6 and C6 0 were cultured in media with or without pyruvate and uridine for 5 days and cell proliferation was measured and compared. After seeding ( $0 \mathrm{~d})$ and growing for $5 \mathrm{days}$ in various media, the number of cells per well was counted. EB, ethidium bromide; ddC, 2',3'-dideoxycytidine; mtDNA, mitochondrial DNA; Con, sample without template; -PU, growth in a medium without pyruvate and uridine; $+\mathrm{PU}$, growth in a medium supplemented with pyruvate and uridine.

Comparisons between two groups were analyzed using unpaired Student's t-test. $\mathrm{P}<0.05$ was considered to indicate a statistically significant difference.

\section{Results}

Effect of EB and ddC treatment on mtDNA content. The mtDNA content decreased with the increase of the treatment time (Fig. 2A). After 6 weeks exposure, the amplification of mtDNA-encoded D-loop region gene was lost in C6 00 cells (42 days), while the parental C6 cells (0 day) yielded strong PCR products at the predicted size. Taken together, the results suggested that mtDNA was specifically depleted from C6 cells and that $\mathrm{C} 6 \rho 0$ cells survived in the culture supplemented with uridine and pyrimidine.

Fig. 2B-a and B-b demonstrated that the single colony of C6 $\rho 0$ and its parent cells were morphologically slightly different. To verify the C6 $\rho 0$ stage of the cloned cells, the growth of $\mathrm{C} 6 \rho 0$ cells was analyzed in the medium without uridine and pyruvate. As shown in Fig. 2B-c and B-d, the number of C $6 \rho 0$ cells became fewer, as they were no longer able to grow in ordinary medium, until their total disappearance. All cells could survive for several days, but at day 5, no living C6 $\rho 0$ cells were identified by the trypan blue exclusion method (Fig. 2B-d). By contrast, C6 $\rho 0$ cells cultured in uridine and pyruvate and C6 cells cultured in selective medium grew vigorously and quickly (Fig. $2 \mathrm{~B}-\mathrm{e}$ ), thus demonstrating that the presence or absence of uridine and pyrimidine had no effect on C6 cell growth, while their presence was essential for the growth of C6 $\rho 0$ cells (Fig. 2C).

Repopulation with exogenous mitochondria from rat platelets. Rat platelets were used as exogenous mitochondrial donors to perform repopulation experiments on the $\mathrm{C} 6 \rho 0$ clone (Fig. 3A). The cybrid cells were analyzed to verify the presence of mtDNA using the mtDNA-specific PCR. As shown in Fig 3B, PCR bands corresponding to mtDNA appeared in both cybrid and wild type C6 cells, suggesting the retention of mtDNA in cybrid cells.

The morphology of mitochondria was significantly different in C6 and C6 $\rho 0$ cells. Wild-type C6 and cybrid cells displayed a typical mitochondrial morphology, with organized cristae, electron-dense matrix and intact mitochondrial membrane (Fig. 3C-a and C-c), while mitochondria in $\mathrm{C} 6 \rho 0$ cells were irregularly expanded, with a partial or almost complete dissolution of the internal cristae (Fig. 3C-b). When the cloned C $6 \rho 0$ cells were fused with rat platelets, the cybrid cells grew well in selective medium without pyruvate and uridine and thus, the repopulated colonies were formed, as shown in Fig. 3D. 


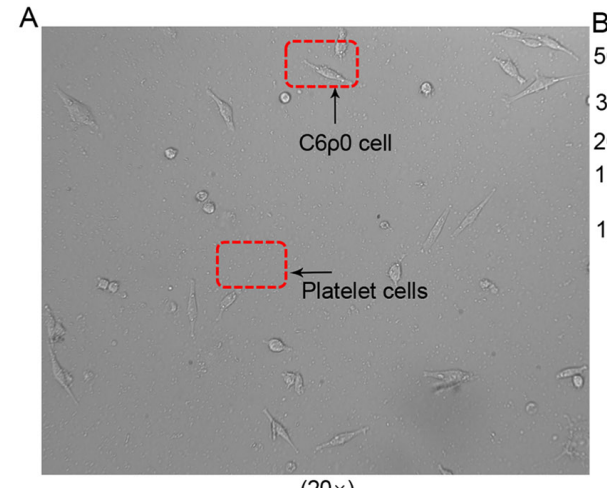

$(20 \times)$
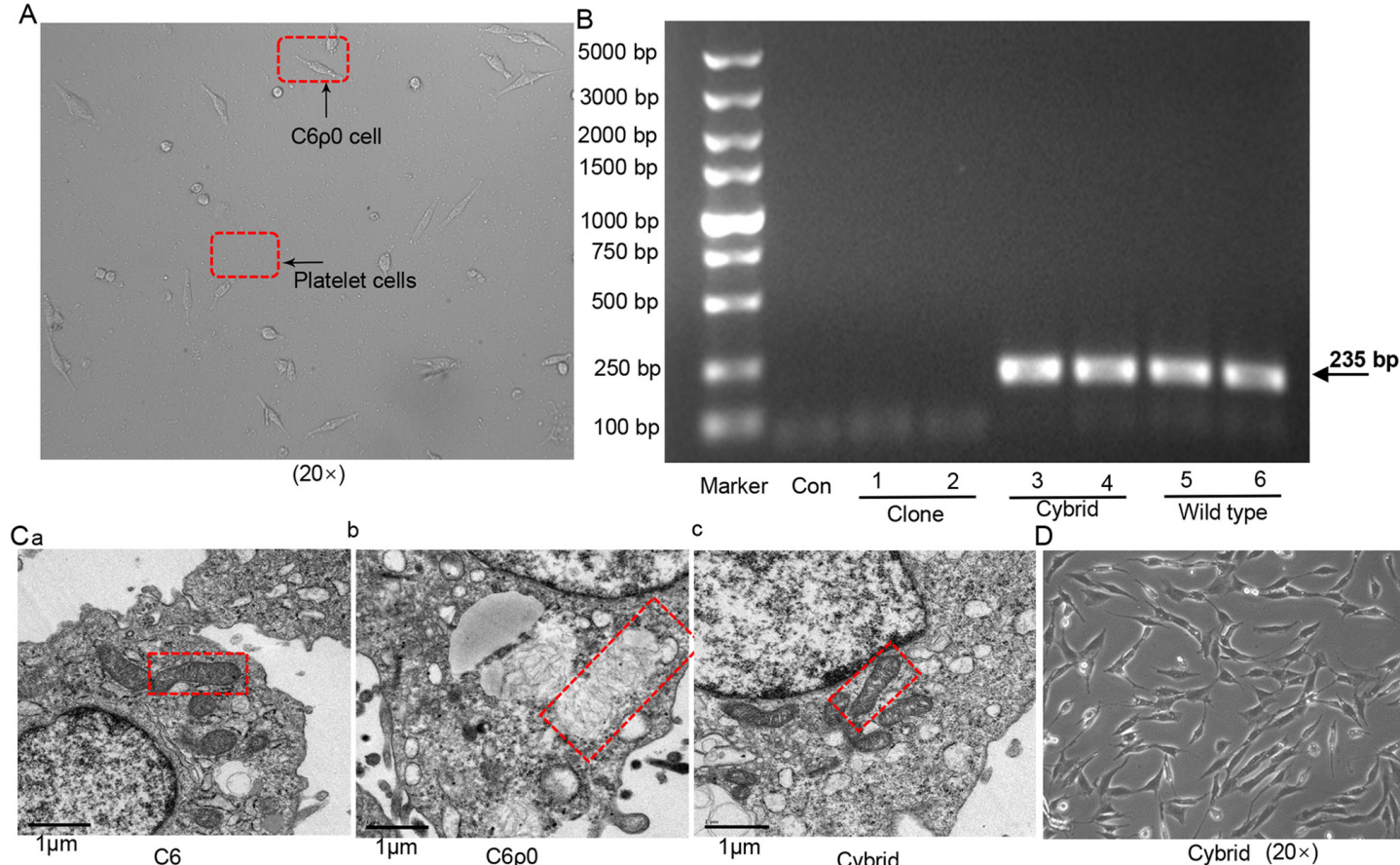

b c D

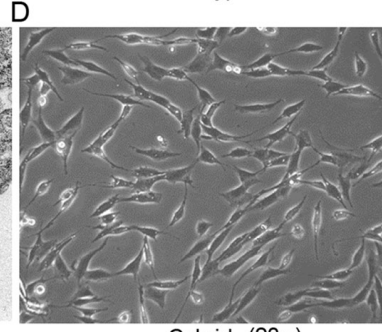

Cybrid

Cybrid (20x)

Figure 3. Construction and identification of cytoplasmic hybrid cells. (A) C6 $\rho 0$ clone fusion with rat platelets: Cybrid cells derived from the fusion between C6 00 clone and platelets isolated from rat blood samples. (B) Presence of mtDNA in cybrid cells and wild-type cells evaluated by mtDNA-specific PCR

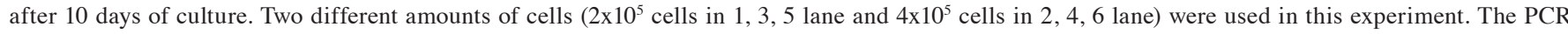
products were visualized on $1 \%$ agarose gel by EB staining. Marker, 5000 DNA ladder. (C) TEM images of (a) C6, (b) C6 $\rho 0$ and (c) cybrid cells (mitochondria indicated by red box), magnification x 25,000 in all cells. (D) Representative image of cybrid cells growing normally in media without pyruvate and uridine. mtDNA, mitochondrial DNA; EB, ethidium bromide; Con, sample without template; Clone, monoclonal C6 00 ; Cybrid, C6 $\rho 0$ cell fused with rat blood platelets; Wild type, C6 cells.

Mitochondrial mass change and sugar uptake in C6 and C6 $\rho 0$. C6 $\rho 0$ cells were characterized by a notable and significant decrease in mitochondrial mass, compared with that in C6 cells $(\mathrm{P}<0.001$; Fig. 4A).

To verify whether the decreased mitochondrial mass had an effect on sugar uptake, the C6 and $\mathrm{C} 6 \rho 0$ cells were exposed to $10 \mu \mathrm{M} 2-\mathrm{NBDG}$ for $30 \mathrm{~min}$ and the sugar content in the cells was evaluated by flow cytometry. Quantitative analysis results showed no difference in sugar uptake between $\mathrm{C6}$ and C6 00 cells (Fig. 4B). However, the ATP assay showed that C6 0 consumed less ATP compared with C6 cells (Fig. 4C).

ROS changes in C6 and C6 $\rho 0$ cells. The amount of total ROS production was significantly reduced in C $6 \rho 0$ cells compared with its production in wild type C6 (Fig. 4D). To evaluate whether this was due to the difference in mitochondria between the two cell types, the source of ROS was identified. The results showed that $\mathrm{C} 6$ cells produced more mitochondrial ROS than C $6 \rho 0$ cells. Some chemicals targeting mitochondria can stimulate $\mathrm{C} 6$ cells to produce more mitochondrial-derived ROS; for instance, rotenone and EB treatment can produce a large amount of mitochondrial ROS in C6 compared with in $\mathrm{C} 6 \rho 0$ (Fig. 4E). This result confirmed that the change in ROS amount between C6 and C6 60 cells was mainly due to the difference in mitochondria; the existence and integrity of mtDNA has a great influence on the production of ROS

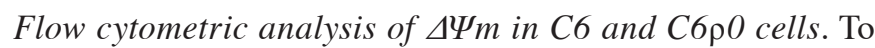
determine the $\Delta \Psi \mathrm{m}$ changes in mtDNA depleted cells, cells were stained with JC-1 and the results of flow cytometry showed a distinct decline in $\Delta \Psi \mathrm{m}$ from untreated $\mathrm{C} 6$ cells, 2-day EB-treated C6 cells and C6 $\rho 0$ monoclonal cells (Fig. 5). These results suggested that the treatment with EB induced a significant decrease in $\Delta \Psi \mathrm{m}$. Thus, the $\Delta \Psi \mathrm{m}$ detected in $\mathrm{C} 6 \rho 0$ cells was reduced by two-thirds compared with $\mathrm{C} 6$ cells.

\section{Discussion}

Mitochondria are the main source of cellular energy and serve a role in cell proliferation, growth and differentiation through continuous fusion and division (21). The mitochondrial genome is essential for a normal cellular function and it encodes important subunits of the mitochondrial respiratory chain and F0F1-ATPase, which are required for oxidative phosphorylation. Depletion of mtDNA results in the inhibition of the mitochondrial respiratory chain and the loss of mtDNA-encoded mitochondrial enzyme activity (16,22-24).

In the present study, persistent mtDNA damage of C6 cells by $\mathrm{EB}$ and ddC successfully induced the $\mathrm{C} 6 \rho 0$ cell phenotype. $\mathrm{EB}$ is known for its insertion in mammalian mtDNA, thus inhibiting mtDNA replication $(25,26)$, and $\mathrm{ddC}$ is used as an antiretroviral drug that can reduce the level of mtDNA by inhibiting mitochondrial DNA polymerase $\gamma$ (27). Therefore, these two compounds have the ability to reduce the amount of mtDNA by interfering with mtDNA replication or inhibiting polymerase $\gamma$.

Indeed, in the present study C6 $\rho 0$ monoclonal cells were successfully obtained through the treatment with the mixture 

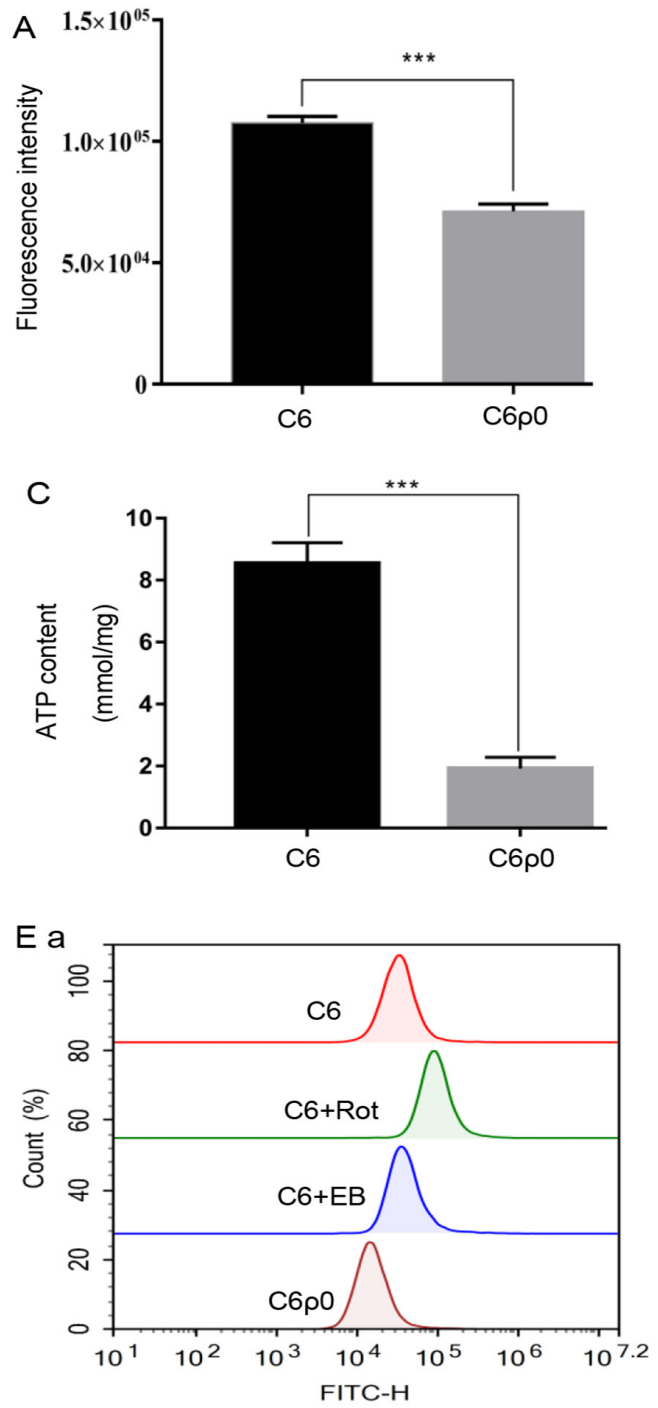
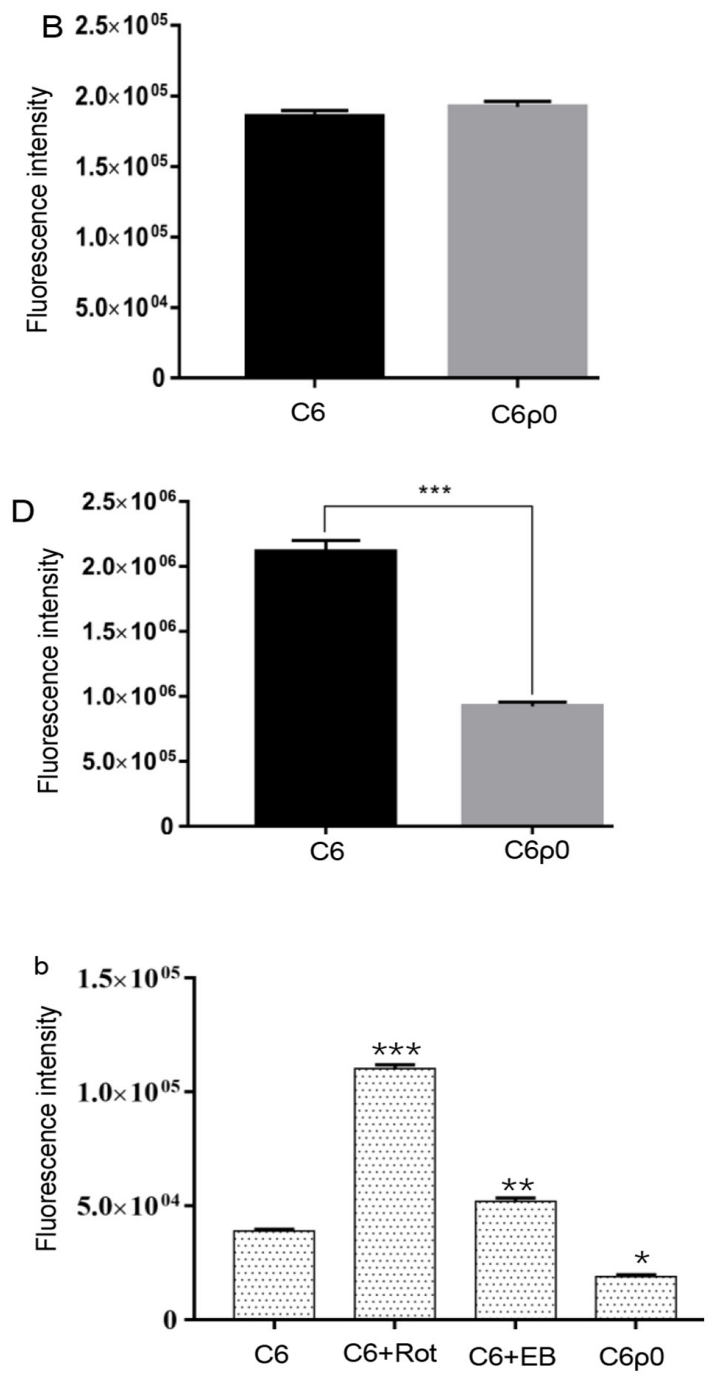

Figure 4. Characteristics of the generated C6 00 and C6 cells. (A) Mitochondrial mass detected by flow cytometry. (B) Quantification of the sugar uptake by

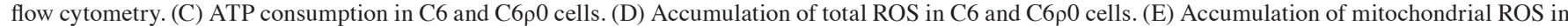
C6 and C6p0 cells. (E-a) Mitochondrial ROS were detected by flow cytometer. (E-b) Fluorescence intensity data were expressed as mean \pm SD. Quantification of the fluorescence intensity; ${ }^{* * *} \mathrm{P}<0.001,{ }^{* * *} \mathrm{P}<0.01$ and ${ }^{*} \mathrm{P}<0.05$ vs. the $\mathrm{C} 6$ group. Comparisons between two groups were analyzed using unpaired Student's t-test and multiple groups were analyzed using one-way ANOVA. $\mathrm{P}<0.05$ was considered to indicate a statistically significant difference. Results are shown as mean \pm standard deviation from three independent experiments. Rot, rotenone; EB, ethidium bromide.

of $\mathrm{EB}$ and $\mathrm{ddC}$ as reported by the literature. As a result, enzymes involved in pyrimidine biosynthesis cannot be activated, resulting in the inability of C6 $\rho 0$ cells to remain alive without uridine and pyruvate (28). The morphology of mitochondria in C6 and C6 $\rho 0$ cells observed by TEM revealed the presence of elongated mitochondria with parallel and normal electron density in the wild-type cells, while disordered swollen mitochondria were found in C6 00 cells. The changes in C $6 \rho 0$ cells were due to the loss of the mitochondrial genome and in agreement with the results of previous studies $(17,20,29)$.

However, not all cell types treated with EB and ddC can result in pure $\rho 0$ cells. Indeed, in the present study HepG2 and Huh7 cells did not lose all their mtDNA following the above treatment (data not shown). This is because not all cells are sensitive to drugs that destroy mtDNA. Thus far, only several cell types can form pure $\rho 0$ cells that can be used for further research $(17,20,26,30)$.
Since mtDNA-depleted cells provide a cytoplasmic hybrid model for studying mtDNA single nucleotide polymorphisms with the same nuclear DNA background, they are considered an effective tool for studying mitochondrial disorders (15). mtDNA and nuclear DNA can control mitochondrial functions and the cybrids allow researchers to evaluate whether the mtDNA or nuclear DNA function is involved in a mitochondrial defect (31). In the present study, a practical and reliable technique was developed to produce $\mathrm{C} 6 \rho 0$ monoclonal cells and cybrids generated with rat platelets. The experiments on the growth characteristics of C6 and C6 $\rho 0$ cells showed that the growth rate of $\mathrm{C} 6 \rho 0$ was significantly reduced compared with the parental cells and that uridine and pyruvate were necessary for their growth. Nevertheless, cybrids grew as much as the wild-type cells and did not need the help of uridine and pyruvate. However, it has been reported that the T47D $\rho 0$, MOLT- $4 \rho 0$, HeLa $\rho 0,143 \mathrm{BTK}^{-} \rho 0$ cells grow slower than their parent cells $(17,20,29,32)$. It is 

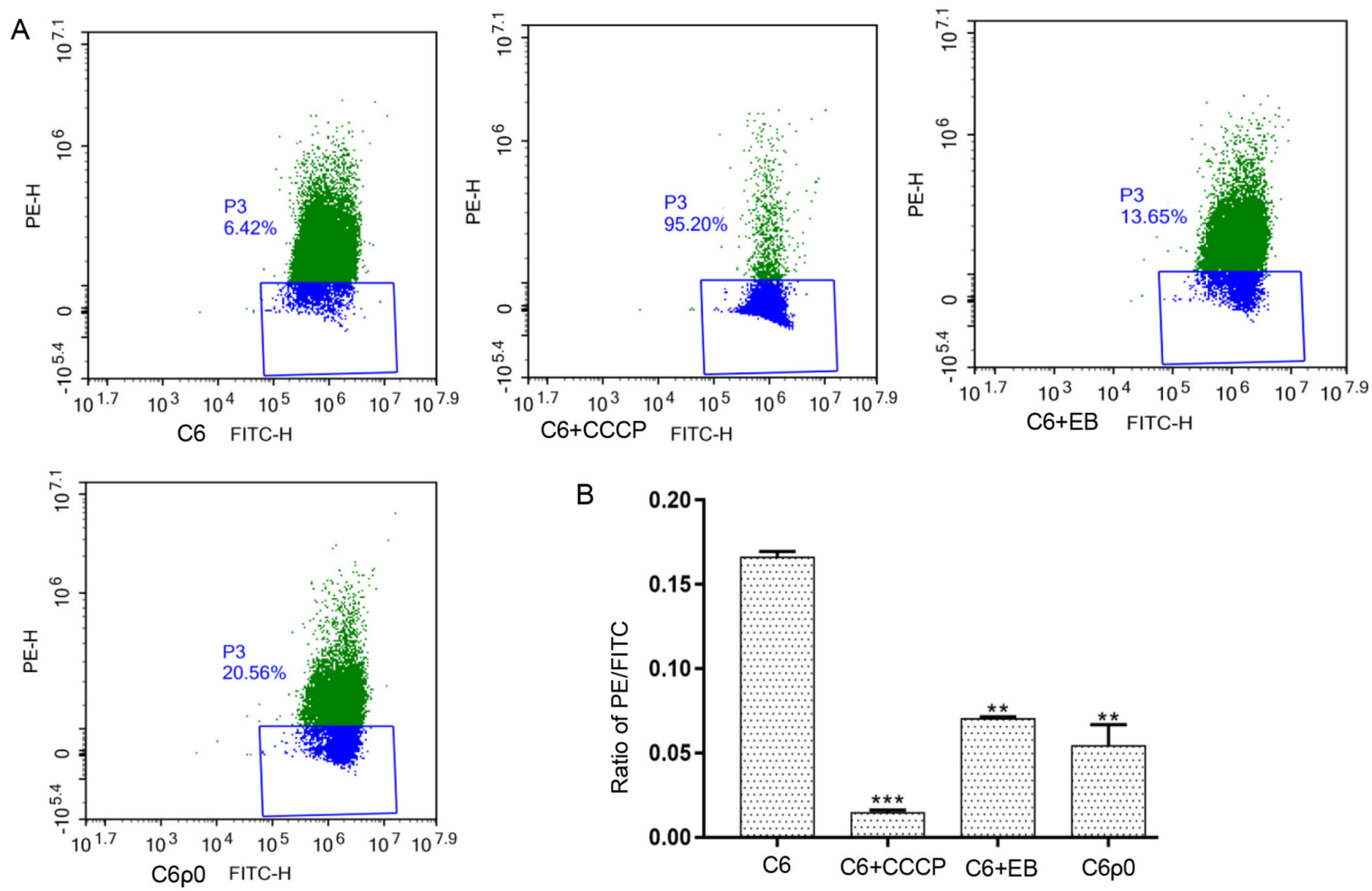

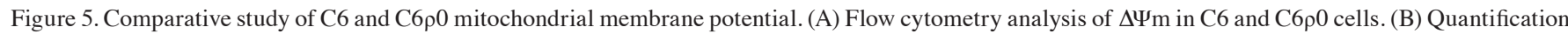
of the fluorescence intensity; ${ }^{* * * *} \mathrm{P}<0.001$ and ${ }^{* *} \mathrm{P}<0.01$ vs. the C6 group (one-way ANOVA). Results are shown as mean \pm standard deviation from three independent experiments. C6, wild-type cells; $\mathrm{C} 6+\mathrm{CCCP}, \mathrm{C} 6$ cells treated with a membrane potential positive agent; $\mathrm{C} 6+\mathrm{EB}, \mathrm{C} 6$ cells treated with EB for 2 days . C6 0 , C6 $\rho 0$ monoclonal cells; CCCP, carbonyl cyanide m-chlorphenizone.

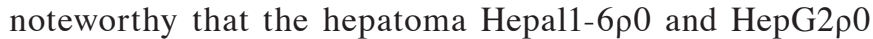
cells proliferate several times more than the wild-type cells, suggesting that different types of cells may exhibit different sensitivities to the intracellular changes caused by mtDNA and not all cell types proliferate less after mtDNA depletion (33).

The number of mitochondria is closely associated with the energy cell metabolism (34). In the present study, the mitochondrial mass of C $6 \rho 0$ cells was notably decreased compared with the mitochondrial mass in C6 cells. The hypothesis was that the decrease of mtDNA content in $\mathrm{C} 6 \rho 0$ cells led to mitochondrial dysfunction and that changes in energy metabolism and ATP content may destroy unconstrained tumor cell proliferation and invasion (35). A series of cellular changes and diseases are closely associated with mtDNA mutations (36). By contrast, some studies have identified that the increasing mtDNA content is a self-protection mechanism that prevents apoptosis and increases tumor cell sensitivity to chemotherapeutic drugs $(37,38)$. The mitochondrial content in the cell determines the apoptotic fate and modulates the time of death, since cells with higher mitochondrial content are more prone to die (39). In fact, the amount of all apoptotic proteins is modulated by the mitochondrial content (40). It is also hypothesized that mtDNA destruction can enhance the apoptosis of certain cells in vivo and inhibit the tumorigenicity of certain tumor cells (41).

Mitochondria are the major source of ROS, which serve key roles in both physiological and pathological processes and act as mediators in a number of cellular signaling pathways in the cell (42). An increase in ROS levels can trigger a protective response by activating antioxidant response elements (43). However, the increase of ROS damages proteins, fats and nucleic acids, triggering other stress responses or cell death $(44,45)$. Conversely, appropriate levels of ROS can reduce cancer, diabetes and delay aging (46). In the present study, the increase in ROS content of rotenone-treated $\mathrm{C} 6$ cells was more than twice that of non-treated C6 cells, while ROS levels in monoclonal C6 $\rho 0$ clearly decreased. These results demonstrated that drugs targeting the complex I, III and V of the respiratory chain $(11,47)$ can cause the increase of ROS, but they have a weak effect on mitochondrial DNA depleted cells.

Mitochondria are key regulators of cell death through alterations in the $\Delta \Psi \mathrm{m}$ to respond to various unfavorable situations. The results of the present study showed that the $\Delta \Psi \mathrm{m}$ in C6 cells was reduced following EB treatment, while the reduction of $\Delta \Psi \mathrm{m}$ in $\mathrm{C} 6 \rho 0$ cells was one third of that of the parent cells. In addition, the C6 $\rho 0$ cells remained alive at relatively low $\Delta \Psi \mathrm{m}$. These results indicated that the complete depletion of the mtDNA in C6 $\rho 0$ cells was not associated to a complete disappearance of the $\Delta \Psi \mathrm{m}$. Some studies have demonstrated that mitochondria with a dysfunctional respiratory chain can still generate $\Delta \Psi \mathrm{m}$ by the use of glycolytic ATP $(18,48)$. A previous study suggested that the change in the membrane status leads to changes in external oxidative stress tolerance and has an influence on the efficacy of cancer therapy (32).

Overall, the method of the present study proved efficient and reliable; the defects in the mitochondrial structure and function in $\mathrm{C} 6 \rho 0$ cells can lead to impairments in cell proliferation in vitro. Therefore, $\mathrm{C} 6 \rho 0$ cell lines with different 
nuclear backgrounds could be used as a model in future experiments to study glioma associated with mitochondria.

\section{Acknowledgements}

Not applicable.

\section{Funding}

The present study was supported by grants from the National Science Foundation of China (grant no. 31870333), Qinghai Provincial Science Foundation (grant no. 2019-ZJ-7023), Qinghai Province International Cooperation Project (grant no. 2018-HZ-812), the Taishan Scholar Program of Shandong Province (grant no. tshw201502046) and the Shuangbai Project of Yantai and Youth Innovation Promotion Association, CAS.

\section{Availability of data and materials}

The datasets used and/or analyzed in the current study are available from the corresponding author upon reasonable request.

\section{Authors' contributions}

HW and ZW conceived the study. JL and BB designed the experiments. YJ and GL performed the experiments. YJ and GL analyzed the data. YJ wrote the manuscript. All authors read and approved the final manuscript.

\section{Ethics approval and consent to participate}

Not applicable.

\section{Patient consent for publication}

Not applicable.

\section{Competing interests}

The authors declare that they have no competing interests.

\section{References}

1. Ostrom QT, Gittleman H, Fulop J, Liu M, Blanda R, Kromer C, Wolinsky Y, Kruchko C and Barnholtz-Sloan JS: CBTRUS statistical report: Primary brain and central nervous system tumors diagnosed in the united states in 2008-2012. Neuro Oncol 17 (Suppl 4): iv1-iv62, 2015.

2. Liu CA, Chang CY, Hsueh KW, Su HL, Chiou TW, Lin SZ and Harn HJ: Migration/invasion of malignant gliomas and implications for therapeutic treatment. Int J Mol Sci 19: 1115, 2018.

3. Chatterjee A, Mambo E and Sidransky D: Mitochondrial DNA mutations in human cancer. Oncogene 25: 4663-4674, 2006.

4. Rocha EM, De Miranda B and Sanders LH: Alpha-synuclein: Pathology, mitochondrial dysfunction and neuroinflammation in Parkinson's disease. Neurobiol Dis 109: 249-257, 2018.

5. Verma P, Singh A, Nthenge-Ngumbau DN, Rajamma U, Sinha S, Mukhopadhyay K and Mohanakumar KP: Attention deficit-hyperactivity disorder suffers from mitochondrial dysfunction. BBA Clin 6: 153-158, 2016.

6. Kraya T, Deschauer M, Joshi PR, Zierz S and Gaul C: Prevalence of headache in patients with mitochondrial disease: A cross-sectional study. Headache 58: 45-52, 2018.
7. Szendroedi J, Phielix E and Roden M: The role of mitochondria in insulin resistance and type 2 diabetes mellitus. Nat Rev Endocrinol 8: 92-103, 2011.

8. Theurey P and Pizzo P: The aging mitochondria. Genes (Basel) 9: 22, 2018.

9. Schapira AH: Mitochondrial disease. Lancet 368: 70-82, 2006.

10. Sharma P and Sampath H: Mitochondrial DNA integrity: Role in health and disease. Cells 8: 100, 2019.

11. Dias N and Bailly C: Drugs targeting mitochondrial functions to control tumor cell growth. Biochem Pharmacol 70: 1-12, 2005.

12. Govindaraj P, Rani B, Sundaravadivel P, Vanniarajan A, Indumathi KP, Khan NA, Dhandapany PS, Rani DS, Tamang R, Bahl A, et al: Mitochondrial genome variations in idiopathic dilated cardiomyopathy. Mitochondrion 48: 51-59, 2019.

13. Spadafora D, Kozhukhar N, Chouljenko VN, Kousoulas KG and Alexeyev MF: Methods for efficient elimination of mitochondrial DNA from cultured cells. PLoS One 11: e0154684, 2016.

14. Yang L, Long Q, Liu J, Tang H, Li Y, Bao F, Qin D, Pei D and Liu X: Mitochondrial fusion provides an 'initial metabolic complementation' controlled by mtDNA. Cell Mol Life Sci 72: 2585-2598, 2015.

15. Chomyn A: Platelet-mediated transformation of human mitochondrial DNA-less cells. Methods Enzymol 264: 334-339, 1996.

16. Yoon YG, Oh YJ and Yoo YH: Rapid isolation of mitochondrial DNA-depleted mammalian cells by ethidium bromide and dideoxycytidine treatments. J App Biol Chem 57: 259-265, 2014.

17. Yu M, Shi Y, Wei X, Yang Y, Zhou Y, Hao X, Zhang N and Niu R: Depletion of mitochondrial DNA by ethidium bromide treatment inhibits the proliferation and tumorigenesis of T47D human breast cancer cells. Toxicol Lett 170: 83-93, 2007.

18. Fernández-Moreno M, Hermida-Gómez T, Gallardo ME, Dalmao-Fernández A, Rego-Pérez I, Garesse R and Blanco FJ: Generating rho-0 cells using mesenchymal stem cell lines. PLoS One 11: e0164199, 2016.

19. Binder DR, Dunn WH Jr and Swerdlow RH: Molecular characterization of mtDNA depleted and repleted NT2 cell lines. Mitochondrion 5: 255-265, 2005.

20. Kukat A, Kukat C, Brocher J, Schäfer I, Krohne G, Trounce IA, Villani G and Seibel P: Generation of rho0 cells utilizing a mitochondrially targeted restriction endonuclease and comparative analyses. Nucleic Acids Res 36: e44, 2008.

21. Holmuhamedova E, Jahangira A, Bienengraebera M, Lewisb LD and Terzic A: Deletion of mtDNA disrupts mitochondrial function and structure, but not biogenesis. Mitochondrion 3: 13-19, 2003.

22. Alston CL, Rocha MC, Lax NZ, Turnbull DM and Taylor RW: The genetics and pathology of mitochondrial disease. J Pathol 241: 236-250, 2017.

23. Meiliana A, Dewi NM and Wijaya A: Mitochondria in health and disease. Indonesian Biomedical J 11: 1-15, 2019.

24. Miller SW, Trimmer PA, Davis Parker W Jr and Davis RE: Creation and characterization of mitochondrial DNA-depleted cell lines with 'neuronal-like' properties. J Neurochem 67: 1897-1907, 1996.

25. Desjardins P, Frost E and Morais R: Ethidium bromide-induced loss of mitochondrial DNA from primary chicken embryo fibroblasts. Mol Cell Biol 5: 1163-1169, 1985.

26. Armand R, Channon JY, Kintner J, White KA, Miselis KA, Perez RP and Lewis LD: The effects of ethidium bromide induced loss of mitochondrial DNA on mitochondrial phenotype and ultrastructure in a human leukemia T-cell line (MOLT-4 cells). Toxicol Appl Pharmacol 196: 68-79, 2004.

27. Nelson I, Hanna MG, Wood NW and Harding AE: Depletion of mitochondrial DNA by ddC in untransformed human cell lines. Somat Cell Mol Genet 23: 287-290, 1997.

28. King MP and Attardi G: Isolation of human cell lines lacking mitochondrial DNA. Methods Enzymol 264: 304-313, 1996.

29. Wochna A, Niemczyk E, Kurono C, Masaoka M, Majczak A, Kedzior J, Slominska E, Lipinski M and Wakabayashi T: Role of mitochondria in the switch mechanism of the cell death mode from apoptosis to necrosis-studies on rho0 cells. J Electron Microsc (Tokyo) 54: 127-138, 2005.

30. Schauen M, Spitkovsky D, Schubert J, Fischer JH, Hayashi J and Wiesner RJ: Respiratory chain deficiency slows down cell-cycle progression via reduced ROS generation and is associated with a reduction of p21CIP1/WAF1. J Cell Physiol 209: 103-112, 2006.

31. Inoue K, Takai D, Hosaka H, Ito S, Shitara H, Isobe K, LePecq JB, Segal-Bendirdjian E and Hayashi J: Isolation and characterization of mitochondrial DNA-less lines from various mammalian cell lines by application of an anticancer drug, ditercalinium. Biochem Biophys Res Commun 239: 257-260, 1997. 
32. Tomita K, Kuwahara Y, Takashi Y, Tsukahara T, Kurimasa A Fukumoto M, Nishitani Y and Sato T: Sensitivity of mitochondrial DNA depleted $\rho 0$ cells to $\mathrm{H}_{2} \mathrm{O}_{2}$ depends on the plasma membrane status. Biochem Biophys Res Commun 490: 330-335, 2017.

33. Boland ML, Chourasia AH and Macleod KF: Mitochondrial dysfunction in cancer. Front Oncol 3: 292, 2013.

34. Vyas S, Zaganjor E and Haigis MC: Mitochondria and Cancer. Cell 166: 555-566, 2016.

35. Penrose HM, Heller S, Cable C, Nakhoul H, Ungerleider N, Baddoo M, Pursell ZF, Flemington EK, Crawford SE and Savkovic SD: In colonic $\rho^{0}$ (rho0) cells reduced mitochondrial function. Oncoscience 4: 189-198, 2017.

36. Pessôa LVF, Bressan FF, Chiaratti MR, Pires PR, Perecin F, Smith LC and Meirelles FV: Mitochondrial DNA dynamics during in vitro culture and pluripotency induction of a bovine Rho0 cell line. Genet Mol Res 14: 14093-14104, 2015.

37. Mei H, Sun S, Bai Y, Chen Y, Chai R and Li H: Reduced mtDNA copy number increases the sensitivity of tumor cells to chemotherapeutic drugs. Cell Death Dis 6: e1710, 2015.

38. Zong WX, Rabinowitz JD and White E: Mitochondria and cancer. Mol Cell 61: 667-676, 2016.

39. Grady JP, Pickett SJ, Ng YS, Alston CL, Blakely EL, Hardy SA, Feeney CL, Bright AA, Schaefer AM, Gorman GS, et al: mtDNA heteroplasmy level and copy number indicate disease burden in m.3243A>G mitochondrial disease. EMBO Mol Med 10: e8262, 2018.

40. Márquez-Jurado S, Díaz-Colunga J, das Neves RP, MartinezLorente A, Almazán F, Guantes R and Iborra FJ: Mitochondrial levels determine variability in cell death by modulating apoptotic gene expression. Nat Commun 9: 389, 2018.
41. Papal S and Skulachev VP: Reactive oxygen species, mitochondria, apoptosis and aging. Mol Cell Biochem 174: 305-319, 1997.

42. Frazier AE, Thorburn DR and Compton AG: Mitochondrial energy generation disorders: Genes, mechanisms, and clues to pathology. J Biol Chem 294: 5386-5395, 2019.

43. Shadel GS and Horvath TL: Mitochondrial ROS signaling in organismal homeostasis. Cell 163: 560-569, 2015.

44. Nunnari J and Suomalainen A: Mitochondria: In sickness and in health. Cell 148: 1145-1159, 2012.

45. Meyer JN, Hartman JH and Mello DF: Mitochondrial toxicity. Toxicol Sci 162: 15-23, 2018.

46. Ristow M, Zarse K, Oberbach A, Klöting N, Birringer M, Kiehntopf M, Stumvoll M, Kahn CR and Blüher M: Antioxidants prevent health-promoting effects of physical exercise in humans. Proc Natl Acad Sci USA 106: 8665-8670, 2009.

47. Zorov DB, Juhaszova M and Sollott SJ: Mitochondrial reactive oxygen species (ROS) and ROS-induced ROS release. Physiol Rev 94: 909-950, 2014.

48. Buchet $\mathrm{K}$ and Godinot C: Functional F1-ATPase essential in maintaining growth and membrane potential of human mitochondrial DNA-depleted rho degrees cells. J Biol Chem 273: 22983-22989, 1998.

(c) () $\Theta$ This work is licensed under a Creative Commons Attribution-NonCommercial-NoDerivatives 4.0 International (CC BY-NC-ND 4.0) License. 